\title{
QUALIDADE DO LEITE DE CABRA IN NATURA E DO PRODUTO PASTEURIZADO ARMAZENADOS POR DIFERENTES PERÍODOS ${ }^{1}$
}

\author{
Carolina Rodrigues da FONSECA ${ }^{2, *}$, Ernani PORTO², Carlos Tadeu dos Santos DIAS ${ }^{3}$, Ivanete SUSIN $^{4}$
}

\begin{abstract}
RESUMO
Foram avaliados diferentes períodos (0,3 e 6 dias) e 2 temperaturas $\left(4^{\circ}\right.$ e $\left.10^{\circ} \mathrm{C}\right)$ no armazenamento do leite de cabra cru e sua influência sobre a qualidade e vida útil do produto pasteurizado. Nos períodos descritos de armazenamento, procedeu-se à pasteurização lenta do leite $\left(65{ }^{\circ} \mathrm{C} / 30 \mathrm{~min}\right)$, sendo o produto processado armazenado a $10{ }^{\circ} \mathrm{C}$ por mais 6 dias. As amostras do leite cru foram caracterizadas imediatamente após a ordenha e após o $3^{\circ}$ e $6^{\circ}$ dias de armazenagem. O leite pasteurizado foi caracterizado imediatamente após a pasteurização e após o $3^{\circ}$ e $6^{\circ}$ dias de armazenagem a $10^{\circ} \mathrm{C}$. Foram realizadas as seguintes análises: contagens de microrganismos mesófilos, psicrotróficos totais, lipolíticos e proteolíticos, coliformes totais e fecais e físico-químicas: acidez, gordura e ácidos graxos livres (AGL). As populações de microrganismos no leite cru tiveram maior desenvolvimento na temperatura de $10{ }^{\circ} \mathrm{C}$ do que a $4{ }^{\circ} \mathrm{C}$. A acidez manteve-se dentro do aceitável na armazenagem a $4{ }^{\circ} \mathrm{C}$ por 6 dias, mas não a $10{ }^{\circ} \mathrm{C}$. Foi observado decréscimo significativo $(\mathrm{p}<0,05)$ no teor de gordura do leite cru durante o armazenamento em ambas as temperaturas e o aumento gradativo da quantidade de ácidos graxos livres (AGL). A pasteurização foi eficiente na redução microbiana, sendo que os microrganismos psicrotróficos lipolíticos e proteolíticos não foram mais detectados após o processo. Contudo, as alterações ocorridas durante o período de estocagem do leite cru influenciaram as características físico-químicas do leite pasteurizado. Durante o armazenamento do leite pasteurizado, os valores de acidez e teor de gordura permaneceram estáveis, enquanto a quantidade de AGL continuou aumentando significativamente. Concluiu-se que o leite de cabra cru pode ser armazenado por até 3 dias a $4{ }^{\circ} \mathrm{C}$, para o produto pasteurizado ter uma vida útil de 6 dias. A temperatura $10^{\circ} \mathrm{C}$ não deve ser utilizada na conservação do leite cru.

Palavras-chave: qualidade de leite, refrigeração do leite, microbiologia do leite, lipólise, caprinos.
\end{abstract}

\begin{abstract}
QUALITY OF IN NATURA GOAT MILK AND PASTEURIZED PRODUCT STORED FOR DIFFERENT PERIODS. Different periods (0, 3 and 6 days) and 2 temperatures $\left(4^{\circ} \mathrm{C}\right.$ and $10{ }^{\circ} \mathrm{C}$ ) of raw goat's milk storage and its impact on pasteurized product quality and shelf life were evaluated. In the described periods, slow pasteurization $\left(65^{\circ} \mathrm{C} / 30 \mathrm{~min}\right)$ was carried out and the pasteurized product was stored at $10{ }^{\circ} \mathrm{C}$ for 6 days. Raw milk samples were characterized after milk handling and after 3 and 6 days of storage. Pasteurized milk was evaluated immediately after heat treatment and after 3 and 6 days of storage at $10^{\circ} \mathrm{C}$. The counting of mesophiles, total, lipolytic and proteolytic psichotrophic bacteria, total and fecal coliforms, acidity, fat and free fatty acid (FFA) contents were determined. The microorganisms' populations had a higher growth at $10{ }^{\circ} \mathrm{C}$ than $4{ }^{\circ} \mathrm{C}$. Acidity remained in acceptable levels during storage at $4{ }^{\circ} \mathrm{C}$ for 6 days, but not at $10^{\circ} \mathrm{C}$. There was a significant decrease $(\mathrm{p}<0.05)$ in raw milk fat content during storage in both temperatures and a gradual increase of free fatty acids (FFA). Pasteurization was efficient in the reduction of bacteria populations and the lipolytic and proteolytic psichrotrophic microorganisms were non-detectable after heat treatment. However, alterations during raw milk storage affected physical-chemical characteristics of pasteurized milk. During storage, values of pasteurized milk acidity and fat content remained stable, while the amount of FFA increased significantly. It was concluded that raw goat's milk can be stored for up to 3 days at $4{ }^{\circ} \mathrm{C}$ before heat treatment. This condition promotes 6 days of shelf-life after pasteurization. In addition, $10{ }^{\circ} \mathrm{C}$ is not a suitable temperature for raw milk conservation.
\end{abstract}

Keywords: milk quality, milk refrigeration, milk microbiology, lipolysis, caprins.

\section{1 - INTRODUÇÃO}

A importância dos caprinos como produtores de carne e leite tem sido discutida e documentada na literatura científica mundial [4, 12, 17].

A indústria leiteira caprina está inserida na indústria leiteira mundial e, conseqüentemente, compete com os produtos

${ }^{1}$ Recebido para publicação em 2/6/2006. Aceito para publicação em 20/10/2006 (001753)

${ }^{2}$ Departamento de Agroindústria Alimentos e Nutrição,

Universidade de São Paulo, Escola Superior de Agricultura

Luiz de Queiroz, (ESALQ/USP),

Av. Pádua Dias, n. 11, C. P. 9, CEP 13416-900, Piracicaba (SP), Brasil

${ }^{3}$ Departamento de Ciências Exatas, (ESALQ/USP),

Av. Pádua Dias, n. 11, C. P. 9, CEP 13416-900, Piracicaba (SP), Brasil

${ }^{4}$ Departamento de Zootecnia, (ESALQ/USP),

Av. Pádua Dias, n. 11, C. P. 9, CEP 13416-900, Piracicaba (SP), Brasil

* A quem a correspondência deve ser enviada lácteos de outras espécies como bovinos, ovinos e bubalinos. Devido ao grande volume de produção de leite bovino, seu menor custo de produção e o seu menor preço no mercado, a produção de leite de cabra e seus derivados destina-se a um nicho de mercado restrito [12]. As pequenas produções individuais e as dificuldades de transporte e industrialização afetam a oferta do leite de cabra in natura no Brasil, deixando muitas vezes como única opção o congelamento e esterilização do leite. Estas dificuldades levam à prática do acúmulo da produção por vários dias, sob refrigeração, antes de ser submetido ao beneficiamento [8].

A microbiota inicial influencia grandemente a qualidade do leite cru e conseqüentemente dos produtos com ele fabricados [19], pois a deterioração é determinada pelo número e tipo de microrganismos presentes. O resfriamento do leite na propriedade rural não permite que as bactérias contaminantes iniciais se reproduzam até o produto ser 
processado industrialmente. Por outro lado, esta prática favorece a seleção de microrganismos beneficiando o crescimento de bactérias psicrotróficas dos gêneros Pseudomonas, Achromobacter, Alcaligenes, Flavobacterium e outras. Estes microrganismos considerados termossensíveis são na maioria das vezes destruídos pela pasteurização, porém produzem enzimas extracelulares (lipases e proteases) que são resistentes a elevadas temperaturas, permanecendo no leite após a pasteurização [14]. A baixa contagem de microrganismos psicrotróficos no leite é de fundamental importância para sua qualidade, pois a atividade metabólica desses microrganismos leva a alterações bioquímicas nos constituintes do leite, as quais limitam a vida de prateleira dos produtos. Uma ampla variedade de problemas relacionados à qualidade de produtos lácteos pode estar associada à ação das lipases e proteases de origem microbiana, como alteração do sabor e odor do leite [9].

\section{2 - MATERIAL E MÉTODOS}

O projeto foi desenvolvido no Laboratório de Higiene e Laticínios do Departamento de Alimentos, Agroindústria e Nutrição da Escola Superior de Agricultura "Luiz de Queiroz" (ESALQ-USP), em Piracicaba, SP.

\section{1 - Coleta e preparo das amostras}

As amostras do leite caprino foram coletadas do latão de armazenamento no Capril da ESALQ/USP, logo após a ordenha da manhã. Utilizaram-se $27 \mathrm{~L}$ para cada repetição. Este leite foi subdividido em latões previamente esterilizados em autoclave (Fabbe-Primmar 103), em 3 amostras de 9 L, uma das quais foi imediatamente submetida ao tratamento térmico a $65{ }^{\circ} \mathrm{C}$ por 30 min e as outras após 3 e 6 dias de refrigeração a $4^{\circ}$ ou $10{ }^{\circ} \mathrm{C}$ (Estufa BOD Tecnal TE-391). Foram realizados 3 experimentos semelhantes para cada temperatura, todos em ocasióes diferentes.

\section{2 - Análises físico-químicas da matéria-prima e do leite de cabra pasteurizado}

Para a caracterização físico-química da matéria-prima (leite de cabra cru) e do leite de cabra pasteurizado, foram analisados o teor de gordura (g/100 g) pelo Método de Babcock e acidez titulável ( $\left.{ }^{\circ} \mathrm{D}\right)$, de acordo com o Standard Methods for the Examination of Dairy Products [2]. O teor de ácidos graxos livres (AGL) foi determinado segundo DEETH et al. [7] e expresso em meq/L de leite.

\section{3 - Análises microbiológicas}

Foram feitas contagens de microrganismos mesófilos $\left(35{ }^{\circ} \mathrm{C} / 48 \mathrm{~h}\right)$ e psicrotróficos aeróbios totais $\left(7^{\circ} \mathrm{C} / 10\right.$ dias $)$ em PCA (Plate Count Agar Difco), psicrotróficos lipolíticos em meio Tributyrin Agar (Merck), utilizando-se a técnica de semeadura em profundidade descrita no Compedium of Methods for the Microbiological Examination of Foods [1]. Os microrganismos psicrotróficos proteolíticos foram inoculados pela técnica de semeadura em superfície, em meio Calcium Caseinate Agar (Merck). Para enumerar os microrganismos psicrotróficos lipolíticos e proteolíticos, foram contadas apenas as colônias típicas (circundadas por um halo característico) nos seus respectivos meios de cultura após a incubação a $7{ }^{\circ} \mathrm{C}$ por 10 dias.

Os coliformes totais e fecais foram determinados pela técnica do número mais provável (NMP), utilizando-se os caldos Lauril Sulfato Triptose (LST Merck) para o teste presuntivo, Verde Brilhante (Merck) para coliformes totais (incubação a $35^{\circ} \mathrm{C}$ por 48 h) e E.c. (Escherichia coli Merck) para os coliformes fecais, após incubação a $44,5{ }^{\circ} \mathrm{C}$ por $24 \mathrm{~h}$ [1].

\section{4 - Tratamento térmico do leite}

As amostras de leite de cabra pasteurizado foram obtidas por pasteurização lenta em banho-maria com circulação (Marconi MA159) a $65{ }^{\circ} \mathrm{C}$ por 30 min do leite cru armazenado, sendo o tempo marcado somente quando o leite atingisse a temperatura do tratamento. A caracterização das amostras de leite de cabra pasteurizado foi idêntica a do leite cru e feita nos dias 0,3 e 6 após o tratamento térmico, sendo o leite pasteurizado armazenado em erlenmeyers sob temperatura controlada de $10^{\circ} \mathrm{C}$.

\section{5 - Análise estatística}

O delineamento experimental utilizado foi o aleatorizado em blocos com esquema fatorial ( 2 temperaturas $x 3$ períodos de armazenamento do leite cru x 3 períodos de armazenamento do leite pasteurizado). Não foi considerada a diferença entre os experimentos realizados na mesma temperatura, mas sim o comportamento de cada tratamento nas repetições e a média geral dos tratamentos. Os resultados obtidos foram analisados conforme análise de variância com aplicação do Teste F. Quando o Teste F foi significativo ao nível de 5\%, a análise estatística teve continuidade, aplicando-se o Teste de comparação múltipla de médias de Tukey, ajustado para o valor-p. Antes da realização da análise, foi feita a análise exploratória dos dados e as variáveis foram transformadas pelo Método Potência Ótima de Box-Cox. Para a análise estatística, utilizou-se o software SAS [18].

\section{3 - RESULTADOS E DISCUSSÃO}

O leite de cabra coletado no dia da ordenha apresentou, respectivamente, para os experimentos realizados a 4 e 10 ${ }^{\circ} \mathrm{C}$, valores médios de $3,43 \pm 0,18$ e 3,40 $\pm 0,15$ (gordura); $15,00 \pm 0,87$ e 15,33 $\pm 0,50$ (acidez); 0,72 $\pm 0,19$ e 0,88 $\pm 0,28$ (ácidos graxos livres) (Tabela 1). Segundo BENEDET \& CARVALHO [3], a composição físico-química do leite de cabra é bastante variável em função de múltiplos fatores, tais como raça, período de lactação, clima, estação do ano, alimentação, idade do animal e produção de leite. A população inicial dos microrganismos no leite cru (Tabela 2) foi menor a 4 ${ }^{\circ} \mathrm{C}$ do que a $10{ }^{\circ} \mathrm{C}$. Entretanto, todas as características da matéria-prima avaliadas no dia da ordenha estavam dentro dos padrões encontrados na literatura $[5,10,15,16]$ e na legislação vigente [6]. 
TABELA 1 - Média dos valores obtidos das características físicoquímicas de leite de cabra cru mantido sob 4 e $10{ }^{\circ} \mathrm{C}$ por 0 , 3 e 6 dias.

\begin{tabular}{ccccc}
\hline Temperatura & $\begin{array}{c}\text { Dias de } \\
\text { armazenamento }\end{array}$ & \multicolumn{3}{c}{ Análises } \\
\cline { 3 - 5 } & & $\begin{array}{c}\text { Acidez } \\
\left({ }^{\circ} \mathbf{D}\right)\end{array}$ & $\begin{array}{c}\text { Gordura } \\
\mathbf{( g / 1 0 0 ~} \mathbf{~ g})\end{array}$ & AGL (meq/L) \\
\hline $4{ }^{\circ} \mathrm{C}$ & 0 & $15,00 \mathrm{a}$ & $3,43 \mathrm{a}$ & $0,72 \mathrm{a}$ \\
& 3 & $16,00 \mathrm{a}$ & $3,36 \mathrm{~b}$ & $0,97 \mathrm{~b}$ \\
& 6 & $15,22 \mathrm{a}$ & $3,28 \mathrm{c}$ & $1,59 \mathrm{c}$ \\
\hline $10{ }^{\circ} \mathrm{C}$ & 0 & $15,33 \mathrm{a}$ & $3,40 \mathrm{a}$ & $0,88 \mathrm{~d}$ \\
& 3 & $17,66 \mathrm{a}$ & $3,26 \mathrm{~d}$ & $1,60 \mathrm{c}$ \\
& 6 & $45,88 \mathrm{~b}$ & n.r. ${ }^{(1)}$ & n.r. \\
\hline
\end{tabular}

Médias seguidas de letras minúsculas diferentes na mesma coluna indicam diferença significativa a $5 \%$ pelo teste de Tukey; ${ }^{(1)}$ Não realizado.

Quando o leite ficou armazenado a $4{ }^{\circ} \mathrm{C}$, não houve diferença significativa $(\mathrm{p}<0,05$ ) entre os valores de acidez (Tabela 1). Apenas o leite armazenado por 6 dias a $10{ }^{\circ} \mathrm{C}$ apresentou valor significativamente maior para acidez, estando o mesmo visivelmente deteriorado, com presença de pequenos coágulos. Por este motivo, as análises para as outras características não foram realizadas.

O teor de gordura apresentou decréscimo significativo durante o armazenamento em ambas as temperaturas. Enquanto o decréscimo entre os dias zero e 3 foi de $0,07 \mathrm{~g} / 100 \mathrm{~g}$ no leite estocado a $4{ }^{\circ} \mathrm{C}$, a diferença foi de $0,14 \mathrm{~g} / 100 \mathrm{~g}$ no leite estocado a $10{ }^{\circ} \mathrm{C}$ para o mesmo período (Tabela 1 ).

O conteúdo de ácidos graxos livres (AGL) aumentou significativamente para todos os períodos de armazenamento (Tabela 1). O valor obtido no sexto dia de estocagem a $4{ }^{\circ} \mathrm{C}$ foi semelhante ao encontrado no terceiro dia de armazenamento a $10{ }^{\circ} \mathrm{C}$. Este dado é condizente com a evolução das bactérias lipolíticas em ambas as temperaturas, conforme pode ser observado na Tabela 2 . O aumento da quantidade de AGL no leite de cabra está intimamente relacionado com o aparecimento do ranço [10]. Os valores obtidos mostram que a temperatura de $10{ }^{\circ} \mathrm{C}$ provocou alterações indesejáveis na matéria-prima em um período de tempo menor quando comparado à temperatura de $4{ }^{\circ} \mathrm{C}$, refletindo negativamente nas características do produto pasteurizado.

A temperatura de armazenagem do produto cru $4{ }^{\circ} \mathrm{C}$ manteve a população de microrganismos mesófilos (Tabela 2) dentro dos limites previstos pela legislação; de $5,00 \times 10^{5} \mathrm{UFC} / \mathrm{mL}$, até o terceiro dia de armazenamento, enquanto que a $10{ }^{\circ} \mathrm{C}$, esse limite já havia sido ultrapassado para o mesmo período de armazenamento. No leite cru a $4{ }^{\circ} \mathrm{C}$, foi verificado aumento de 1,0 e 1,1 ciclos logarítmicos, respectivamente, do dia da coleta ao terceiro e sexto dias. A $10{ }^{\circ} \mathrm{C}$ o crescimento observado foi de 2,6 e 1,0 ciclos para os mesmos períodos.

Os microrganismos psicrotróficos (Tabela 2), ao contrário do que ocorreu com a população dos mesófilos, tiveram taxa de crescimento semelhante em ambas as temperaturas e atingiram contagens próximas nas duas temperaturas de estocagem após 6 dias. A $10{ }^{\circ} \mathrm{C}$ foi encontrado aumento de 3,8 ciclos logarítmicos, do dia zero ao sexto dia, valor próximo ao encontrado para o leite estocado a $4{ }^{\circ} \mathrm{C}(3,2$ ciclos $)$. Apesar da taxa de crescimento ter sido semelhante para as duas temperaturas, a população dos microrganismos psicrotróficos alcançou população em torno de $10^{6} \mathrm{UFC} / \mathrm{mL}$ no terceiro dia de armazenamento quando o leite ficou a $10{ }^{\circ} \mathrm{C}$, a qual já é crítica para a qualidade do produto de acordo com LÜCK et al. [13].

O crescimento dos microrganismos psicrotróficos lipolíticos e proteolíticos (Tabela 2) foi maior a $10{ }^{\circ} \mathrm{C}$ do que a $4{ }^{\circ} \mathrm{C}$, o que seria esperado. A $10{ }^{\circ} \mathrm{C}$, a população destes microrganismos ultrapassou $10^{6} \mathrm{UFC} / \mathrm{mL}$ no terceiro dia de estocagem. A $4{ }^{\circ} \mathrm{C}$ esses microrganismos atingiram população de $6,02 \times 10^{4}$ e $2,00 \times 10^{5} \mathrm{UFC} / \mathrm{mL}$ (lipolíticos e proteolíticos, respectivamente), ultrapassando $10^{6} \mathrm{UFC} / \mathrm{mL}$ somente no sexto dia (Tabela 2). Embora esses microrganismos sejam bastante termolábeis e destruídos pela pasteurização, a estocagem na temperatura de $4{ }^{\circ} \mathrm{C}$ garante maior qualidade, pois as enzimas desses microrganismos são termorresistentes e atuam mesmo após a pasteurização. Quando o leite cru foi armazenado a $10{ }^{\circ} \mathrm{C}$, houve aumento de 4,9 ciclos

TABELA 2 - Média dos valores obtidos das características microbiológicas de leite de cabra cru mantido sob 4 e $10{ }^{\circ} \mathrm{C}$ por 0,3 e 6 dias.

\begin{tabular}{lcccc}
\hline \multicolumn{1}{c}{ Microrganismos } & Temperatura $\left({ }^{\circ} \mathrm{C}\right)$ & \multicolumn{3}{c}{ Dias de armazenamento } \\
\cline { 3 - 5 } & & $\mathbf{0}$ & $\mathbf{3}$ & $\mathbf{6}$ \\
\hline Mesófilos (UFC/mL) & 4 & $5,21 \times 10^{4}\left(4,3^{*}\right)$ & $2,27 \times 10^{5}(5,3)$ & $2,76 \times 10^{6}(6,4)$ \\
& 10 & $1,58 \times 10^{5}(5,2)$ & $6,60 \times 10^{7}(7,8)$ & $6,89 \times 10^{8}(8,8)$ \\
\hline Psicrotróficos totais (UFC/mL) & 4 & $1,58 \times 10^{4}(4,2)$ & $1,76 \times 10^{5}(5,2)$ & $2,59 \times 10^{7}(7,4)$ \\
& 10 & $1,31 \times 10^{5}(5,1)$ & $6,09 \times 10^{7}(7,8)$ & $7,37 \times 10^{8}(8,9)$ \\
\hline Psicrotróficos lipolíticos (UFC/mL) & 4 & $3,49 \times 10^{3}(3,5)$ & $6,02 \times 10^{4}(4,8)$ & $1,16 \times 10^{8}(8,1)$ \\
& 10 & $6,40 \times 10^{4}(4,8)$ & $3,21 \times 10^{7}(7,5)$ & $2,53 \times 10^{8}(8,4)$ \\
\hline Psicrotróficos proteolíticos (UFC/mL) & 4 & $6,78 \times 10^{3}(3,8)$ & $2,00 \times 10^{5}(5,3)$ & $1,41 \times 10^{8}(8,1)$ \\
& 10 & $5,26 \times 10^{3}(3,7)$ & $2,52 \times 10^{7}(7,4)$ & $3,69 \times 10^{8}(8,6)$ \\
\hline Coliformes totais (NMP/mL) & 4 & $1,68 \times 10^{2}(2,2)$ & $2,10 \times 10^{2}(2,3)$ & $2,10 \times 10^{2}(2,3)$ \\
& 10 & $3,15 \times 10^{3}(3,5)$ & $1,17 \times 10^{7}(7,1)$ & $1,57 \times 10^{8}(8,2)$ \\
\hline Coliformes fecais (NMP/mL) & 4 & 0,7 & 1,0 & 1,0 \\
\end{tabular}

$\left({ }^{*}\right)$ Valores entre parênteses indicam o valor logarítmico. 
logarítmicos dos microrganismos psicrotróficos proteolíticos do dia zero ao sexto dia, sendo o crescimento do dia zero ao dia 3 de 3,7 ciclos.

Os coliformes totais e fecais (Tabela 2 ) tiveram crescimento intenso durante o armazenamento a $10^{\circ} \mathrm{C}$. Embora o leite recém ordenhado estivesse de acordo com a qualidade exigida pela legislação, houve proliferação intensa durante a armazenagem nessa temperatura, chegando a uma população extremamente elevada ao sexto dia $\left(1,57 \times 10^{8} \mathrm{NMP} / \mathrm{mL}\right)$, a qual ultrapassou os limites permitidos e inclusive deteriorando o produto cru. Por este motivo, o leite cru estocado a $10{ }^{\circ} \mathrm{C}$ por 6 dias não resistiu à pasteurização, interrompendo a caracterização do leite pasteurizado neste caso. Já a temperatura de $4{ }^{\circ} \mathrm{C}$ controlou efetivamente essa população e, especialmente para estes grupos, o controle da temperatura mostrou-se um fator muito importante para a qualidade do leite.

Na Figura 1, observa-se que a pasteurização empregada $\left(65{ }^{\circ} \mathrm{C} / 30 \mathrm{~min}\right)$ reduziu muito a população microbiana, mesmo no leite armazenado por maior período, o qual apresentava maiores contagens de microrganismos no leite cru. Logo após o tratamento térmico, as amostras de leite apresentaram contagens de microrganismos mesófilos semelhantes, independente da população mais elevada no leite cru.

A pasteurização do leite $\left(65^{\circ} \mathrm{C} / 30 \mathrm{~min}\right)$ reduziu a população de microrganismos mesófilos a contagens similares, independente da temperatura de estocagem do leite cru $\left(4^{\circ}\right.$ ou $10^{\circ} \mathrm{C}$ ) e de sua população após a estocagem por 3 dias (Figura 1). Como o leite cru mantido a $10{ }^{\circ} \mathrm{C}$ por 6 dias não resistiu à pasteurização, foram realizadas análises apenas dos dias 0 e 3 de armazenamento.

As amostras de leite cru refrigerado a $4{ }^{\circ} \mathrm{C}$, que apresentavam contagens elevadas de microrganismos psicrotróficos lipolíticos e proteolíticos, não apresentaram contagens detectáveis destes microrganismos logo após a pasteurização (Figura 1). Isso demonstra que estes microrganismos são bastante sensíveis à pasteurização, mas também indica que o processo térmico pode mascarar a má qualidade do leite. Apesar de serem destruídos durante a pasteurização do leite, estes microrganismos liberam enzimas lipolíticas e proteolíticas termorresistentes durante a estocagem do leite cru, causando alterações indesejáveis no produto pasteurizado, conforme FONSECA \& SANTOS [9].

Durante a avaliação da vida útil do produto pasteurizado (por até 6 dias), o número de microrganismos mesófilos manteve-se estável. A Instrução Normativa 37, que estabelece a qualidade do leite de cabra pasteurizado [6], permite contagem de mesófilos de até $10^{4} \mathrm{UFC} / \mathrm{mL}$, estando todas as amostras estudadas dentro dos padrões (contagens entre $2,96 \times 10^{2}$ e $4,29 \times 10^{3} \mathrm{UFC} / \mathrm{mL}$ ). Os microrganismos psicrotróficos apresentaram reduzida variação, negativa ou positiva, durante o armazenamento do produto pasteurizado, com contagens variando entre $<10$ e 4,66 x $10^{2} \mathrm{UFC} / \mathrm{mL}$.

Em todas as amostras de leite pasteurizado analisadas, não houve a detecção de coliformes fecais ou totais em

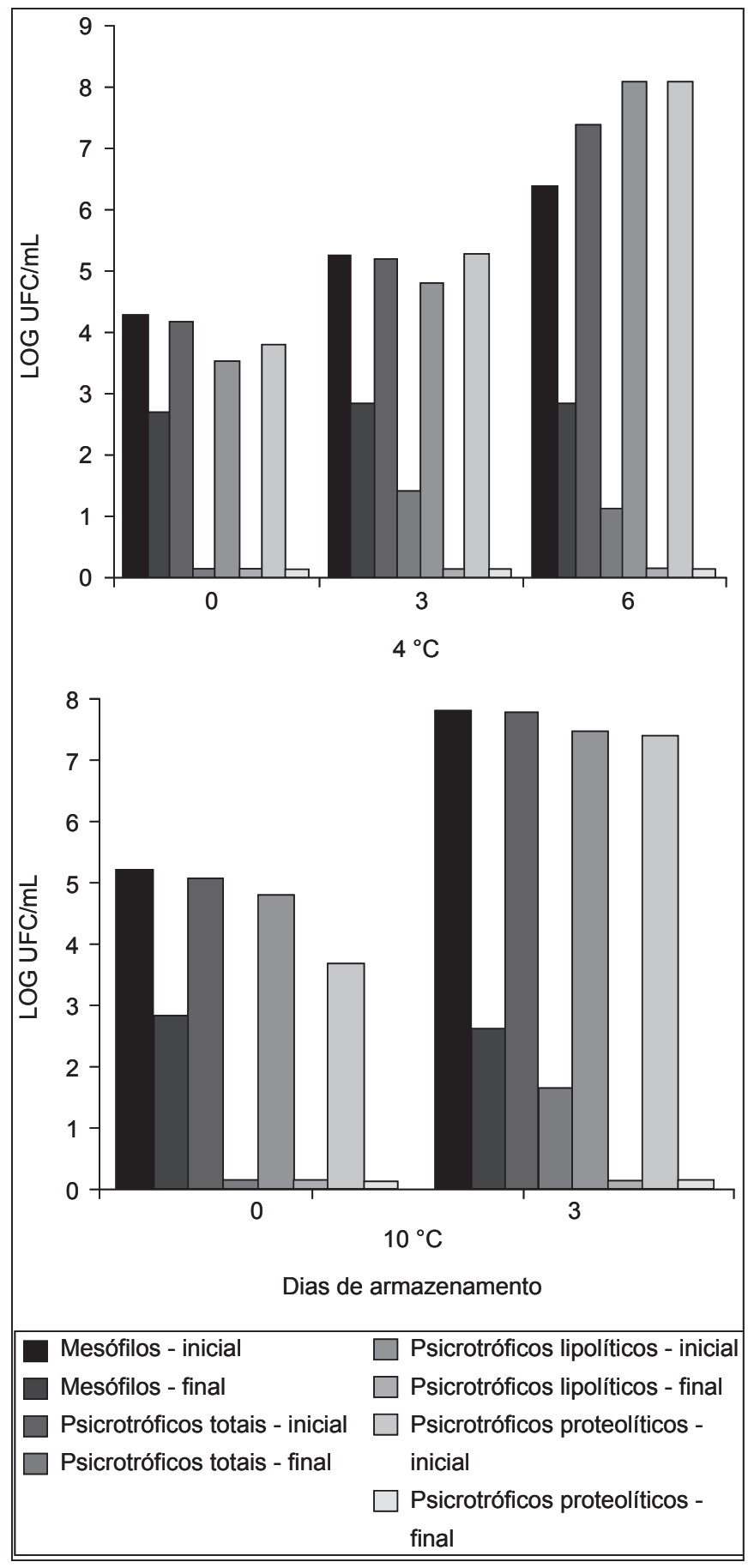

FIGURA 1 - Populações microbianas antes e após a pasteurização de leite de cabra mantido refrigerado por até 6 dias a $4{ }^{\circ} \mathrm{C}$ e 3 dias a $10{ }^{\circ} \mathrm{C}$.

$1 \mathrm{~mL}$ da amostra, resultados semelhantes ao relatado por FERREIRA et al. [8]. A legislação permite até 2,0 coliformes totais/mL e exige a ausência de coliformes fecais, estando todas as amostras do presente trabalho dentro do previsto na legislação. Contudo, no caso da armazenagem a $10{ }^{\circ} \mathrm{C}$ por 3 dias do leite cru, a população de coliformes totais, que era de $1,17 \times 10^{7} \mathrm{NMP} / \mathrm{mL}$, foi reduzida a níveis não detectáveis. Isso mostra mais uma vez que a pasteurização é eficiente e pode mascarar a má qualidade do leite cru arma- 
zenado a $10{ }^{\circ} \mathrm{C}$ por 3 dias, mas comprometerá a qualidade do produto pasteurizado.

A Tabela 3 mostra os valores encontrados para acidez do leite pasteurizado. Observou-se a estabilização dos valores após o tratamento térmico, havendo diferença significativa $(\mathrm{p}<0,05)$ apenas entre as amostras de leite pasteurizado obtido de leite cru armazenado por 3 dias a $10{ }^{\circ} \mathrm{C}$ e as demais. Conforme foi discutido anteriormente, pode-se observar que a acidez do leite armazenado nessas condições já estava acima do recomendado pela legislação brasileira e, embora a pasteurização tenha garantido a qualidade microbiológica no tocante aos coliformes, comprometeria uma série de processos tecnológicos posteriores. Já quando o leite cru foi armazenado a $4{ }^{\circ} \mathrm{C}$, os valores de acidez estiveram muito próximos e sempre dentro do aceitável mesmo após 6 dias de armazenagem pasteurizado, independente do período de estocagem cru.

TABELA 3 - Média dos valores obtidos para acidez $\left({ }^{\circ} \mathrm{D}\right)$ em leite de cabra pasteurizado, mantido a $10{ }^{\circ} \mathrm{C}$ por diferentes períodos.

\begin{tabular}{ccccc}
\hline \multirow{2}{*}{$\begin{array}{c}\text { Temperatura de } \\
\text { armazenamento } \\
\text { do leite cru }\end{array}$} & $\begin{array}{c}\text { Dias de arma- } \\
\text { zenamento do } \\
\text { leite cru }\end{array}$ & \multicolumn{3}{c}{$\begin{array}{c}\text { Dias de armazenamento do } \\
\text { leite pasteurizado }\end{array}$} \\
\cline { 3 - 5 } & 0 & $\mathbf{0}$ & $\mathbf{3}$ & $\mathbf{6}$ \\
\hline $4{ }^{\circ} \mathrm{C}$ & 3 & $15,33 \mathrm{aA}$ & $15,33 \mathrm{aA}$ & $15,44 \mathrm{aA}$ \\
& 6 & $15,77 \mathrm{aA}$ & $16,22 \mathrm{aA}$ & $15,00 \mathrm{aA}$ \\
& 0 & $15,77 \mathrm{aA}$ & $14,55 \mathrm{aA}$ & $14,44 \mathrm{aA}$ \\
\hline $10^{\circ} \mathrm{C}$ & 3 & $22,66 \mathrm{aB}$ & $22,33 \mathrm{aB}$ & $23,11 \mathrm{aB}$ \\
& 6 & n.r. ${ }^{(1)}$ & n.r. & n.r. \\
\hline
\end{tabular}

Médias seguidas de letras diferentes, minúsculas na mesma linha e maiúsculas na mesma coluna, indicam diferença significativa a $5 \%$ pelo teste de Tukey; ${ }^{(1)}$ Não realizado.

O teor de gordura também se manteve estável durante o armazenamento do produto pasteurizado (Tabela 4), havendo diferença significativa apenas entre as amostras de leite com 0 e 6 dias de armazenamento, obtidas do tratamento térmico do leite resfriado a $10{ }^{\circ} \mathrm{C}$ no dia da coleta. Essas variações podem ser atribuídas às enzimas lipolíticas microbianas termorresistentes ou até mesmo à exatidão do método de análise utilizado. Ao comparar as médias entre as colunas, notou-se diferença entre as amostras de leite pasteurizado obtido de leite cru armazenado a $4{ }^{\circ} \mathrm{C}$ por 0 e 6 dias, indicando que o armazenamento do leite cru não deve ser feito por um período tão longo nesta temperatura. Isso pode ser reflexo da população de microrganismos lipolíticos que se desenvolveu durante esse período, conforme se observou na Tabela 2. Deste modo, para o produtor ter um leite com a melhor qualidade possível, o recomendado é um período de estocagem de 3 dias. Acima disso, pode haver comprometimento de suas características, embora ainda não esteja visivelmente deteriorado.

Após a pasteurização do leite, a quantidade de AGL continuou aumentando (Tabela 5). Este aumento de AGL no leite provavelmente está relacionado com o crescimento dos microrganismos psicrotróficos no leite ainda cru e que produziram enzimas lipolíticas termorresistentes, concordando com o descrito por MOURA [14]. De fato, como se
TABELA 4 - Média dos valores obtidos para teor de gordura em leite de cabra pasteurizado, mantido a $10{ }^{\circ} \mathrm{C}$ por diferentes períodos.

\begin{tabular}{cllcc}
\hline \multirow{2}{*}{$\begin{array}{c}\text { Temperatura de } \\
\text { armazenamento } \\
\text { do leite cru }\end{array}$} & $\begin{array}{c}\text { Dias de arma- } \\
\text { zenamento do } \\
\text { leite cru }\end{array}$ & & \multicolumn{3}{c}{$\begin{array}{c}\text { Dias de armazenamento do } \\
\text { leite pasteurizado }\end{array}$} \\
\cline { 3 - 5 } & & $\mathbf{0}$ & $\mathbf{3}$ & $\mathbf{6}$ \\
\hline $4{ }^{\circ} \mathrm{C}$ & 0 & $3,51 \mathrm{aA}$ & $3,46 \mathrm{aA}$ & $3,41 \mathrm{aA}$ \\
& 3 & $3,40 \mathrm{aAB}$ & $3,42 \mathrm{aA}$ & $3,39 \mathrm{aA}$ \\
& 6 & $3,35 \mathrm{aB}$ & $3,30 \mathrm{aB}$ & $3,26 \mathrm{aB}$ \\
\hline $10^{\circ} \mathrm{C}$ & 0 & $3,55 \mathrm{aA}$ & $3,41 \mathrm{abA}$ & $3,36 \mathrm{bA}$ \\
& 3 & $3,38 \mathrm{aA}$ & $3,28 \mathrm{aB}$ & $3,27 \mathrm{aA}$ \\
& 6 & n.r. ${ }^{(1)}$ & n.r. & n.r. \\
\hline
\end{tabular}

Médias seguidas de letras diferentes, minúsculas na mesma linha e maiúsculas na mesma coluna, indicam diferença significativa a $5 \%$ pelo teste de Tukey; ${ }^{(1)}$ Não realizado.

observou na Tabela 2 , o crescimento das bactérias lipolíticas foi mais intenso a $10{ }^{\circ} \mathrm{C}$ do que a $4{ }^{\circ} \mathrm{C}$, justificando esses valores. GOMES [11] cita, para leite bovino, que valores de ácidos graxos livres acima de 1,3 meq/L geralmente tornam o produto inaceitável. Com base nestes valores, o leite de cabra cru poderia ser armazenado cru por até 3 dias a $4{ }^{\circ} \mathrm{C}$ e, após a pasteurização, ainda teria vida útil de 6 dias. Já quando houve a estocagem do leite cru a $10{ }^{\circ} \mathrm{C}$, as amostras de leite pasteurizado apresentaram valores de AGL bem acima de 1,3 meq/L depois de armazenado pelo mesmo período, afetando sua qualidade.

TABELA 5 - Média dos valores obtidos para quantidade de ácidos graxos livres (meq/L) em leite de cabra pasteurizado, mantido a $10{ }^{\circ} \mathrm{C}$ por diferentes períodos.

\begin{tabular}{ccccc}
\hline \multirow{2}{*}{$\begin{array}{c}\text { Temperatura de } \\
\text { armazenamento } \\
\text { do leite cru }\end{array}$} & $\begin{array}{c}\text { Dias de arma- } \\
\text { zenamento do } \\
\text { leite cru }\end{array}$ & \multicolumn{3}{c}{$\begin{array}{c}\text { Dias de armazenamento do } \\
\text { leite pasteurizado }\end{array}$} \\
\cline { 3 - 5 } & 0 & $\mathbf{0}$ & $\mathbf{3}$ & $\mathbf{6}$ \\
\hline $4{ }^{\circ} \mathrm{C}$ & 3 & $0,50 \mathrm{aA}$ & $0,73 \mathrm{aA}$ & $1,17 \mathrm{bA}$ \\
& 6 & $1,50 \mathrm{aC}$ & $1,08 \mathrm{abB}$ & $1,30 \mathrm{bA}$ \\
& 0 & $1,31 \mathrm{aC}$ & $1,62 \mathrm{bC}$ & $2,10 \mathrm{cB}$ \\
\hline $10{ }^{\circ} \mathrm{C}$ & 3 & $2,22 \mathrm{aD}$ & $2,48 \mathrm{aD}$ & $2,78 \mathrm{bBC}$ \\
& 6 & n.r. $(1)$ & n.r. & n.r. \\
\hline
\end{tabular}

Médias seguidas de letras diferentes, minúsculas na mesma linha e maiúsculas na mesma coluna, indicam diferença significativa a $5 \%$ pelo teste de Tukey; ${ }^{(1)}$ Não realizado.

\section{4 - CONCLUSÕES}

$\mathrm{O}$ armazenamento do leite cru por diferentes períodos a 4 e $10{ }^{\circ} \mathrm{C}$ influenciou a qualidade do produto pasteurizado. Quanto maior a temperatura e o período de estocagem do leite cru, pior foi a qualidade do produto pasteurizado e menor a sua vida útil. Apesar da acidez e do teor de gordura terem se estabilizado no leite pasteurizado, a quantidade de ácidos graxos livres continuou aumentando, indicando a ação de enzimas lipolíticas termorresistentes produzidas durante a estocagem do leite cru. De acordo com os resultados encontrados no presente trabalho, o leite de cabra cru pode ser mantido por até 3 dias a $4{ }^{\circ} \mathrm{C}$ antes do tratamento térmico para que o produto pasteurizado tenha vida útil de 6 dias. A temperatura de estocagem de $10{ }^{\circ} \mathrm{C}$ não deve ser utilizada como instrumento na conservação do leite cru. 


\section{5 - REFERÊNCIAS BIBLIOGRÁFICAS}

[1] AMERICAN PUBLIC HEALTH ASSOCIATION - APHA Compendium of methods for the microbiological examination of foods. 4. ed. Washington, DC: American Public Health Association, 2001. 676p.

[2] AMERICAN PUBLIC HEALTH ASSOCIATION - APHA Standard methods for the examination of dairy products. 16. ed. Washington, DC: American Public Health Association, 1992. 345p.

[3] BEnEdeT, H. D.; CARVAlHO, M. W. Caracterização de leite de cabra no Estado de Santa Catarina, Brasil. Ciência e Tecnologia de Alimentos, Campinas, v. 16, n. 2, p. 116-119, 1996.

[4] BOYAZOGLU, J.; MORAND-FEHR, P. Mediterranean dairy sheep and goat products and their quality. A critical review. Small Ruminant Research, Amsterdam, v. 40, n. 1, p. 1-11, 2001.

[5] BRASIL, L. H. A.; WECHESLER, F. S.; BACCARI JÚNIOR, F.; GONÇALVES, H. C.; BONASSI, I. A. Efeitos do estresse térmico sobre a produção, composição química do leite e respostas termorreguladoras de cabras da raça alpina. Revista Brasileira de Zootecnia, Viçosa, v. 29, n. 6, p. 1632-1641, 2000.

[6] BRASIL. Ministério da Agricultura e do Abastecimento. Secretaria de Defesa Agropecuária. Regulamento Técnico de produção, identidade e qualidade do leite de cabra. Instrução Normativa n ${ }^{\circ} 37$ de 31 de outubro de 2000. Diário Oficial da União, Brasília, 8 de novembro de 2000.

[7] DEETH, H. C.; FITZ-GERALD, C. H.; WOOD, A. F. A convenient method for determining the extent of lipolysis in milk. The Australian Journal of Dairy Technology, Melbourne, v. 30, n. 1, p. 109-111, 1975.

[8] FERREIRA, C. L. L. F., THAMA, S. F. M. S., NEUMANN, E. Qualidade microbiológica do leite de cabra armazenado a $4^{\circ} \mathrm{C}$, tratado termicamente e mantido sob refrigeração por sete dias. Revista do Instituto de Laticínios Cândido Tostes, Juiz de Fora, v. 47, n. 279/281, p. 37-40, 1992.

[9] FONSECA, L. F. L., SANTOS, M. V. Qualidade do leite e controle de mastite. 1. ed. São Paulo: Lemos Editorial, 2000.

[10] GOMES, M. I. F. V. Alterações na qualidade do leite pasteurizado pela lipase microbiana. 1988, 85p.
Dissertação (Mestre em Agronomia) - Escola Superior de Agricultura Luiz de Queiroz, Universidade de São Paulo, Piracicaba, 1988.

[11] GOMES, M. I. F. V., BONASSI, I. A., ROÇA, R. O. Características químicas, microbiológicas e sensoriais de leite de cabra congelado. Ciência e Tecnologia de Alimentos, Campinas, v. 17, n. 2, p. 111-114, 1997.

[12] HAENLEIN, G. F. W. Goat milk in human nutrition. Small Ruminant Research, Amsterdam, v. 51, n. 2, p. 155-163, 2004.

[13] LÜCK, H.; DYNKELD, M.; BERG, M. V. D. Shelf life tests on pasteurized milk. South African Journal of Dairy Technology, Johannesburg, v. 12, n. 1, p. 107-112, 1980.

[14] MOURA, C. J. Efeito do resfriamento do leite sobre o rendimento e lipólise do queijo tipo parmesão. 1997. 77p. Dissertação (Mestre em Ciência dos Alimentos) - Universidade Federal de Lavras, Lavras, 1997.

[15] OLIVEIRA JUNIOR, R. C.; SUSIN, I. PIRES, A. V.; SIMAS, J. M. C.; MORAIS, J. B. Desempenho de cabras em lactação alimentadas com grão de soja. Acta Scientiarum, Maringá, v. 24, n. 4, p. 1113-1118, 2002.

[16] POIATTI, M. L. Avaliação da qualidade microbiológica e físico-química de leite cru, pasteurizado e congelado de cabra. 2001, 61p. Dissertação (Mestre em Zootecnia) - Faculdade de Ciências Agrárias e Veterinárias, Universidade Estadual Paulista Júlio de Mesquita Filho, Jaboticabal, 2001.

[17] RUBINO, R.; MORAND-FEHR, P.; RENIERI, C.; PERAZA C.; SARTI, F. M. Typical products of the small ruminant sector and the factors affecting their quality. Small Ruminant Research, Amsterdam, v. 34, n. 3, p. 289-302, 1999.

[18] SAS Institute Inc. User's guide for SAS software navigator. 9. ed. Cary, NC: SAS Institute Inc., 2003. 22p.

[19] SUAREZ, B.; FERREIROS, C. M. Psichrotrophic flora of raw milk: resistance to several common desinfectants. Journal of Dairy Research, London, v. 58, n. 1, p. 127-136, 1991.

\section{6 - AGRADECIMENTO}

Os autores agradecem à Fapesp (Fundação de Amparo à Pesquisa de São Paulo) pelo financiamento do projeto. 